\title{
Debris flow impact estimation on a rigid barrier
}

\author{
Federico Vagnon ${ }^{1}$ and Andrea Segalini ${ }^{2}$ \\ ${ }^{1}$ Department of Earth Sciences, University of Turin, 10135 Turin, Italy \\ ${ }^{2}$ Department of Civil-Environmental Engineering and Architecture, University of Parma, 43124 Parma, Italy \\ Correspondence to: Federico Vagnon (fvagnon@unito.it)
}

Received: 9 March 2016 - Published in Nat. Hazards Earth Syst. Sci. Discuss.: 22 March 2016

Revised: 16 June 2016 - Accepted: 1 July 2016 - Published: 22 July 2016

\begin{abstract}
The aim of this paper is to analyse debris flow impact against rigid and undrained barrier in order to propose a new formulation for the estimation of acting force after the flow impact to safe design protection structures. For this reason, this work concentrates on the flow impact, by performing a series of small scale tests in a specifically created flume. Flow characteristics (flow height and velocity) and applied loads (dynamic and static) on barrier were measured using four ultrasonic devices, four load cells and a contact surface pressure gauge. The results obtained were compared with main existing models and a new equation is proposed. Furthermore, a brief review of the small scale theory was provided to analyse the scale effects that can affect the results.
\end{abstract}

\section{Introduction}

Every year several gravitational movements, such as debris flows, landslides and avalanches, affect mountainous regions all over the world. Understanding and predicting their interactions with protection structures is a key point for the assessment and the management of risk.

Debris flow impact estimation requires us to analyse and to discuss two key points: the first one is the data availability, deriving from real case observation, to validate the proposed models; the second one is related to the universal applicability of these equations.

Concerning the first point, the difficulties to find available data derived from monitoring of debris flow events force to perform laboratory experiments (Armanini and Scotton, 1992; Huebl and Holzinger, 2003; Canelli et al., 2012) due to the high instrumentation costs.
Furthermore, laboratory tests allow to keep under strict control all the parameters involved and to easily perform several analyses. On the other hand, the question about the scale effects it is not completely solved: many authors raised doubts about the acceptability of the results carried out with these experiments (Iverson, 1997).

The design of mitigation structures requires simple models to predict impact pressure with high reliability; these models should be universally recognized and should include few parameters, easy to estimate. Moreover, material properties and flow characteristics should be considered in the equations. Following these preconditions, an accurate study of the flow behaviour against structures is necessary in order to define European criteria for design of debris flows protection fences.

This paper presents the first results of several laboratory tests performed to reduce the lack of information about impact force prediction.

\section{Small scale theory}

The possibility to simulate debris flows in laboratory is a controversial argument; even if the similarity theory provides the necessary support to design models and to extrapolate the data at the real scale, the scale effects plays an important role in the comprehension of the phenomenon (Longo, 2011). In particular, while geometric similarity $(\lambda)$ can be easily obtained as the ratio of the prototype length $\left(L^{\prime \prime}\right)$ and laboratory conditions $\left(L^{\prime}\right)$, the major limit is represented by the dynamic similarity of all forces because are strictly related to the nature and the viscosity of the fluid (Iverson, 1997).

These issues were faced starting from an accurate dimensional analysis of the impact of a saturated mass against a rigid wall. The longitudinal deformation of this structure is 
the key parameter that allows us to evaluate the energy dissipation of the mass. From this point of view, the mean density of saturated debris $\rho_{\mathrm{m}}$, the flow velocity $v_{\mathrm{f}}$, the flow height $h_{\mathrm{f}}$, and the channel width $B$, play a fundamental role in the characterization of the mobilized mass. On the other hand, the impact and the debris retention behind the barrier are related to elastic module $E$, yield stress $\sigma_{0}$, and shape factor of the barrier. Thus, the maximum barrier deformation can be expressed as follows:

$\delta=f\left(\rho_{\mathrm{m}}, v, h_{\mathrm{f}}, B, E, \sigma_{0}\right.$, shape $)$.

The similarity criteria produces these conditions:

$$
\left\{\begin{array}{l}
r_{\delta}=r_{\mathrm{B}} \\
\lambda=r_{\mathrm{B}} \\
r_{\sigma_{0}}=r_{\rho_{\mathrm{m}}} \cdot r_{\mathrm{v}}^{2}, \\
r_{\mathrm{E}}=r_{\rho_{\mathrm{m}}} \cdot r_{\mathrm{v}}^{2} \\
r_{\mathrm{v}}=\sqrt{\lambda}
\end{array}\right.
$$

where $r$ is the scale ratio.

In order to take these relationships into account, the Froude similarity was applied to the examined experimental tests. The scientific community agrees with the theory that values obtained from small scale tests are acceptable if the Froude number of the simulated current is comparable with the real ones (Hübl et al., 2009; Longo, 2011; Canelli et al., 2012; Scheidl et al., 2013). The open question deals with the maximum acceptable Froude number for small scale results; some authors (Hübl et al., 2009) suggest that the maximum acceptable Froude number for debris flow simulated in laboratory is 3 , but it is demonstrated that debris flow in nature can assume Froude numbers greater than this value (Costa, 1984). Furthermore, small Froude number means high velocity value and, simultaneously, high thickness (and vice versa). However, these conditions do not satisfy the characteristic of the majority of Alpine debris flows, which are characterized by high velocity (greater than $10 \mathrm{~m} \mathrm{~s}^{-1}$ ) and relatively shallow depths (ranging from 0.2 to $1.5 \mathrm{~m}$ ). For these reasons the authors decided to normalize force values, dividing the measured force by the hydrostatic force of the current and compared all the results with the corresponding Froude number.

\section{Experimental setup and measuring procedure}

Experiments were performed in a steel flume $4 \mathrm{~m}$ long and $0.39 \mathrm{~m}$ wide, in which a rigid barrier was positioned orthogonally at the channel bottom. The slope is variable between 30 and $35^{\circ}$. The flow was started by the sudden emptying of a hopper into the flume (Fig. 1).

Four ultrasonic level measurers were mounted along the centre line of the channel at a known distance, decreasing progressively near the barrier. These devices had an acquisition frequency of $1 \mathrm{kHz}$ and were used to evaluate both flow

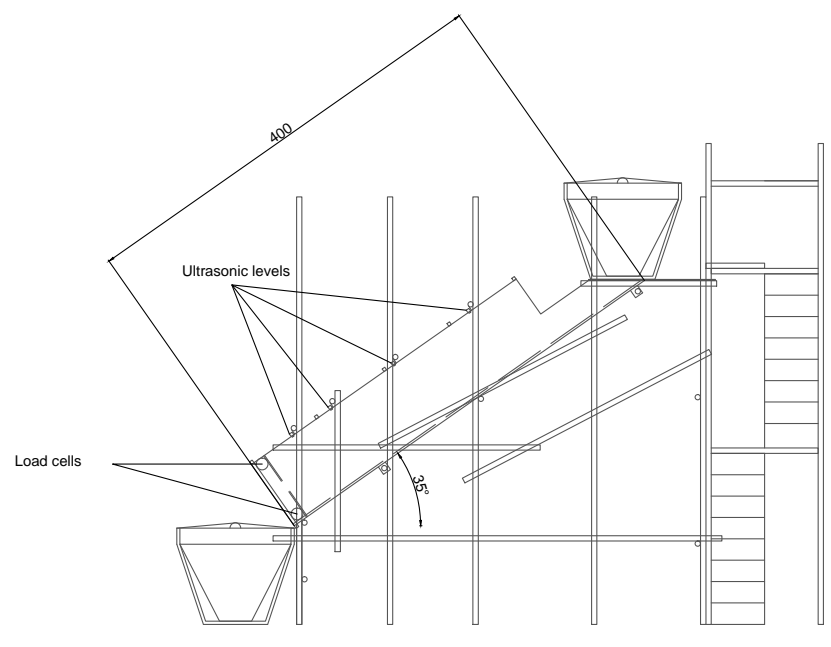

Figure 1. Scheme of the flume and of the starting mechanism.

height and impact velocity on the barrier. Four load cells were installed at the plate vertices to measure the normal thrust acting on the barrier.

Flow velocity at the barrier was estimated as the ratio of the distance between last ultrasonic level and the barrier location, and the difference between the time of first arrival of the front flow and the time of impact at the barrier. To observe the trend of the flow rate in the flume, the velocity values were evaluated at each sensor's interval.

A contact surface pressure gauge was used to control the evolution of the impact load at the barrier. This device, called Tactilus ${ }^{\circledR}$, is produced by Sensor Products LLC, and is designed to display a picture of the pressure distribution, measure and calculate min/max pressure, generate 2-D and 3$\mathrm{D}$ modelling and region of interest viewing. It is made by a matrix of $32 \times 32$ piezoresistive sensors and allowed us to capture and record pressure conditions with a sampling frequency of $50 \mathrm{~Hz}$ (Fig. 2). To limit the possible formation of layers of air between the gauge and the barrier during the impact and to prevent to overestimate the impact load (Bagnold, 1939), the sensor was forced to adhere to the structure. This system is very useful to understand the behaviour of the flow during the impact because it allows us to verify the zones mainly stressed and confirms the hypothesis made on the determination of the peak impact force. In fact, observing Fig. 2, the pressure distribution assumes the typical triangular shape but the pressure values are greater than those expected: this confirms the hypothesis of a dominant dynamic component. Furthermore, the Tactilus ${ }^{\circledR}$ allows us to check the force values measured using load cells, with the advantage that in every point of the barriers it is possible to know the corresponding instant load values. In the experimental tests, this device was also used to verify the occurrence of vertical wave overpressure. The capability to record impact pressure in real time allows us to understand and to detect the most stressed zones of the barrier. In this way, it is possible to verify the 


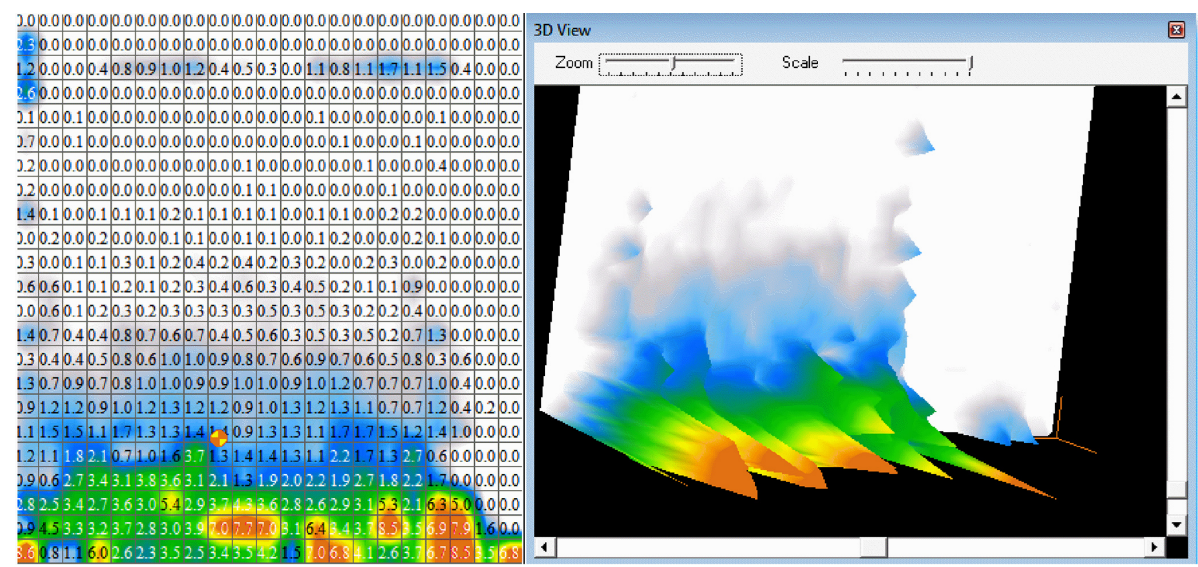

Figure 2. 2-D and 3-D impact representation registered by Tactilus ${ }^{\circledR}$ pressure sensor.

Table 1. Main initial properties of the mixture used.

\begin{tabular}{lll}
\hline \multicolumn{3}{c}{ Mixture main initial properties } \\
\hline Friction angle & $\varphi^{\prime}\left[^{\circ}\right]$ & 29 \\
Density of the grain & $\rho_{\mathrm{S}}\left[\mathrm{kg} \mathrm{m}^{-3}\right]$ & 2630 \\
Density of the flow & $\rho_{\mathrm{f}}\left[\mathrm{kg} \mathrm{m}^{-3}\right]$ & 1920 \\
Solid volume fraction & $C_{\mathrm{S}}$ & 0.6 \\
Fluid volume fraction & $C_{\mathrm{f}}$ & 0.4 \\
Savage number & $N_{\mathrm{Sav}}$ & 0.144 \\
Bagnold number & $N_{\text {Bag }}$ & 888 \\
Mass number & $N_{\text {Mass }}$ & 3.75 \\
Darcy number & $N_{\text {Dar }}$ & 576 \\
Reynolds number & $N_{\text {Rey }}$ & 236 \\
Friction number & $N_{\text {Fric }}$ & 6628 \\
\hline
\end{tabular}

accuracy of the hypotheses done about the behaviour of the current during the impact.

The tests were performed using saturated sand. The main characteristics of the material are listed in Table 1 and its grain-size distributions is shown in Fig. 3. The choice to use sand as the mixture material was made to obtain and easily check the characteristics of the flow. It is well known that the grain size distribution used is not exhaustive and representative of a real debris flow (which is generally made up of a very wide range of grain sizes), but the authors wanted to avoid, at this stage of the study, the formation of over pressures due to the impact of boulders and their interactions inside the mixture. Furthermore, there is the necessity to consider a homogeneous fluid scheme to evaluate the peak thrust.

However, to verify that the simulated currents could be assimilated to debris flows, the six dimensionless parameters recommended by Iverson's theory (Iverson, 1997) were calculated (Table 1). Obviously, the estimated values are referred to the initial conditions. This is a simplification, but it is possible to consider that the Bagnold number, Darcy number and Savage number do not vary considerably during the flow. Therefore, when these values fall into the debris flow

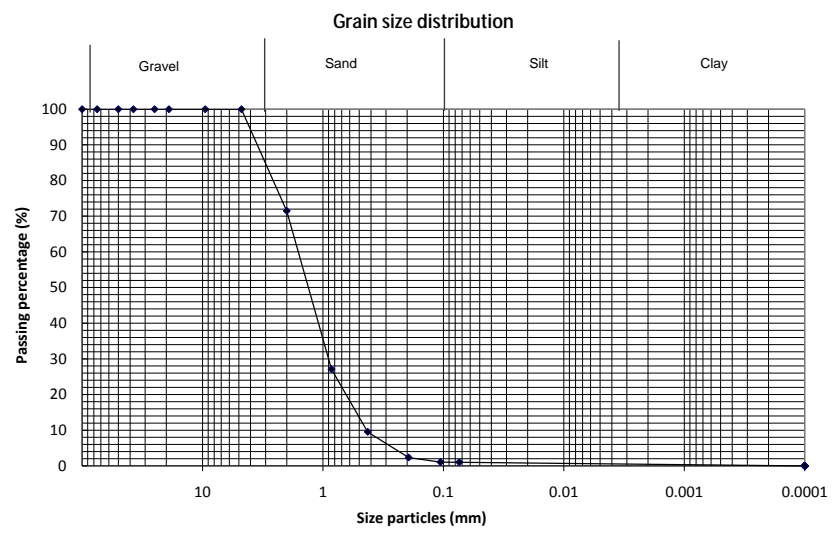

Figure 3. Grain size distribution of the mixture.

region obtained from Iverson's theory, the mixture can be considered as a debris flow.

In this first stage of the study, only rigid and waterproof barrier was used, in order to reduce the possible deformations and consequently to correctly evaluate the force and better understand the dynamics of the impact.

\section{Analytical approach}

Several models were hypothesized to estimate the impact force of debris flow against rigid barrier. In particular, the impact force can be proportional either to hydrostatic pressure or kinetics flow height. Thus, three groups of relations can be used: hydro-static, hydro-dynamic and mixed models.

The equations referred to the first group have the following aspect:

$F_{\text {peak }}=k \cdot \rho_{\mathrm{m}} \cdot g \cdot h_{\mathrm{f}} \cdot A$,

where $F_{\text {peak }}$ is the maximum impact thrust in $\mathrm{N}, k$ is an empirical coefficient, $\rho_{\mathrm{m}}$ is the mean density of the debris im- 
pacting fluid in $\mathrm{kg} \mathrm{m}^{-3}, g$ is gravity in $\mathrm{m} \mathrm{s}^{-2}, h_{\mathrm{f}}$ is the flow height in $\mathrm{m}$ and $A$ is the impact surface in $\mathrm{m}^{2}$.

This formula is very popular because it only requires debris density and flow height and usually flow height is considered equal to channel depth. The only limit is represented by $k$ factor that can assume values ranging from 2.5 to 11 (Lichtenhahn, 1973; Armanini, 1997; Scotton and Deganutti, 1997).

Hydro-dynamic models derive from the application of the momentum balance of the thrust under the hypothesis of homogeneous fluid; impact force can be evaluated as follows:

$F_{\text {peak }}=\alpha \cdot \rho_{\mathrm{m}} \cdot v_{\mathrm{f}}^{2} \cdot A$,

where $\alpha$ is a dynamic coefficient and $v_{\mathrm{f}}$ is the flow velocity in $\mathrm{m} \mathrm{s}^{-1}$.

The dynamic coefficient is the key point of this relation; it depends on the flow type, on the formation of a vertical jetlike wave during the impact and on the barrier type (Canelli et al., 2012). In particular, the drainage capability of the barrier reduces the magnitude of this coefficient due to the rapid discharge of the fluid portion through the barrier, preventing the formation of wave overpressure. Another aspect to take into account while choosing $\alpha$ is the grain size distribution of the debris flow: if it is predominantly coarse, the dynamic coefficient is greater since there is a local overpressure build up due to the impact of single boulders on the barrier.

In scientific literature, there is a wide range of proposed values for dynamic coefficient: Hungr et al. (1984) propose $\alpha$ equal to 1.5, Daido (1993) suggests values varying between 5 and 12, Zhang (1993) recommends a range between 3 and 5, Bugnion et al. (2011) hypothesizes value from 0.4 to 0.8 , and Canelli et al. (2012) hypothesizes value between 1.5 and 5 . From the values listed above it is clear that the range of variation of dynamic coefficient (between 0.4 and 12) deeply conditions the flow peak force and consequently the design of protection structures.

Furthermore, there are others formulations derived from hydro-dynamic relation. Huebl and Holzinger (2003) relate the Froude number $(F r)$ to normalised impact force and provide the following expression:

$F_{\text {peak }}=5 \cdot \rho_{\mathrm{m}} \cdot v_{\mathrm{f}}^{0.8} \cdot\left(g \cdot h_{\mathrm{f}}\right)^{0.6} \cdot A$.

Zanuttigh and Lamberti (2004), considering the total reflection of a current against a vertical wall and, imposing the dynamic equilibrium, propose the following relation:

$F_{\text {peak }}=C_{\mathrm{c}} \cdot \frac{(1+\sqrt{2} F r)^{2}}{2} \cdot \rho_{\mathrm{m}} \cdot g \cdot h_{\mathrm{f}} \cdot A$,

where $C_{\mathrm{c}}$ is an empirical coefficient calibrated considering the vertical acceleration caused by the presence of fine particles and boulder.

Another equation to evaluate the dynamic impact of a debris flow against a vertical wall is presented by Armanini et al. (2011):
$\widetilde{F}_{\text {peak }}=\left(1+\frac{1}{2} \cdot F r^{2}\right) \cdot\left(1+\frac{\alpha \cdot F r^{2}}{1+\frac{1}{2} \cdot F r^{2}}\right)$,

where $\alpha$ is a coefficient equal to 1 .

The mixed models consider both the hydro-static and the hydro-dynamic effects (Cascini et al., 2000; Arattano and Franzi, 2003; Brighenti et al., 2013); the general equation is the following:

$F_{\text {peak }}=\frac{1}{2} \cdot \rho_{\mathrm{m}} \cdot g \cdot h_{\mathrm{f}} \cdot A+\rho_{\mathrm{m}} \cdot v^{2} \cdot A$.

Lately Jiang and Zhao (2015) proposed a new formulation for impact force estimation, introducing the influence of the tangential forces during the impact due to the friction between flow and wall.

Combining the data obtained using the surface pressure gauge and flow characteristics (depositional height and velocity), we propose the following equation to estimate impact force on a rigid wall:

$$
\begin{aligned}
F_{\text {peak }} & =F_{\text {stat }}+F_{\text {dyn }} \pm F_{\text {drag }}=\frac{1}{2} \cdot \rho_{\mathrm{m}} \cdot g \cdot K_{\mathrm{a}} \\
& \cdot\left(H_{\max }^{2}-h_{\mathrm{f}}^{2}\right) \cdot B \cdot \cos \theta+\alpha \cdot \rho_{\mathrm{m}} \cdot v_{\mathrm{f}}^{2} \cdot A \\
& \cdot \cos \beta-\rho_{\mathrm{m}} \cdot g \cdot h_{\mathrm{f}} \cdot \tan \varphi^{\prime} \operatorname{cdot} \frac{H_{\mathrm{max}}-h_{\mathrm{f}}}{\sin \theta} \\
& \cdot \cos \beta \cdot \cos \theta \cdot B,
\end{aligned}
$$

where $F_{\text {stat }}$ is the active earth force, $F_{\text {dyn }}$ is the dynamic force, $F_{\mathrm{drag}}$ is the drag force (all the forces are evaluated in N), $K_{\mathrm{a}}$ is active lateral earth pressure coefficient derived from Rankine theory, $\theta$ is slope angle in $\operatorname{deg}, \beta$ is the angle between the barrier and the normal at channel bottom, measured in deg, and $H_{\max }$ is the maximum filling height behind the barrier in $\mathrm{m}$ (see Fig. 4).

Since static, dynamic, and drag force do not reach their maximum value at the same time during the debris flow impact, $H_{\max }$ should be considered equal to the height of the barrier $H_{\mathrm{B}}$ in order to obtain the peak load. In this way, the static force reaches its maximum value.

The sign of the drag force depends on whether the current overflows or not the barrier. On one hand if there is overflow, the sign of the drag force is positive because it induces a deformation at the top of the barrier; on the other hand the sign is negative because the flow produces a friction with the deposited material that reduces the dynamic effects.

This formulation contains both the intrinsic material characteristics, represented by static internal friction angle $\varphi$ and density $\rho_{\mathrm{m}}$, and flow conditions, depicted by flow height $h_{\mathrm{f}}$ and current velocity $v_{\mathrm{f}}$; moreover, the shape of the barrier, in terms of height $H_{\mathrm{B}}$ and width $B$, and channel inclination are considered. In particular, including the shape of the barrier in the peak force calculation, the formula provides an innovative approach, since equations listed above are referred to 


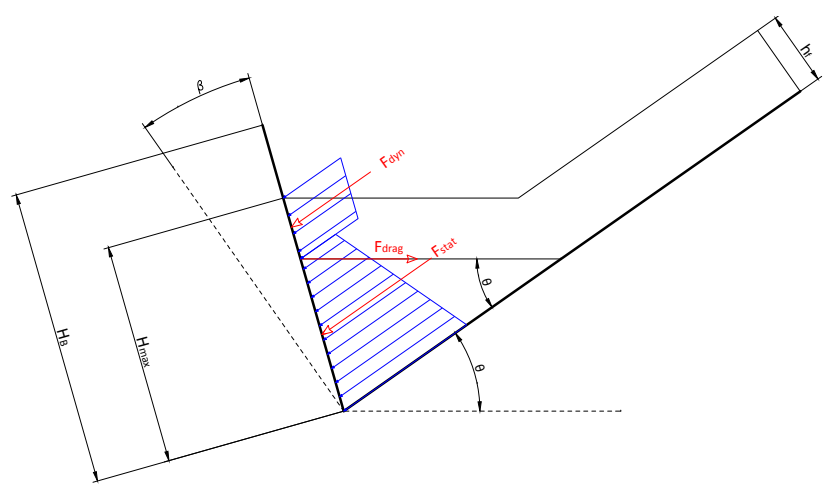

Figure 4. Scheme of flow impact and assumed filling process for the calculation of dynamic, static and drag load on the rigid barrier.

flow conditions. In fact, in these formulations there are no references to the channel condition in terms of inclination and dimension, while the equation proposed introduces these parameters.

The estimation of the static internal friction angle was done using the tilting box method (Burkalow, 1945); moreover, to verify the value obtained, a back analysis was carried out deriving the internal friction angle from the static force measured by pressure device.

No measurements of bulk density variation were carried out during the impact phase; this value was hypothesized to be constant according to the theory of incompressible fluid.

Flow height and velocity were obtained using ultrasonic devices.

In order to follow the scale principles described in Sect. 2, Eq. (9) has been normalized by the hydro-static force relative to the impacting front, obtaining

$$
\begin{aligned}
F_{\text {peak }} & =\frac{F_{\text {peak }}}{\rho_{\mathrm{m}} \cdot g \cdot h_{\mathrm{f}} \cdot A}=\frac{1}{2} \cdot K_{\mathrm{a}} \cdot\left(n^{2}-1\right) \cdot \cos \theta \\
& +\alpha \cdot F r^{2} \cdot \cos \beta-\tan \varphi^{\prime} \cdot \frac{n-1}{\sin \theta} \cdot \cos \beta \cdot \cos \theta,
\end{aligned}
$$

where $n$ is the filling ratio and $F r$ the Froude number of the current.

About the filling ratio, it is the ratio between the maximum filling height behind the barrier and the flow height; this number allows us to relate flow thickness to barrier dimension.

When $n$ is equal to 1 , the dimensionless force is reduced to Eq. (4). This means that if the barrier is hit by a volume moderately small, composed by only one surge, the peak force is totally governed by dynamic component.

\section{Validation of the proposed model}

Analysing the trend of the total impact force in time (Fig. 5), the hypothesized model is confirmed. In fact, it is possible to highlight how the peak force acting on the barrier can be assumed as the sum of two components: one in which static

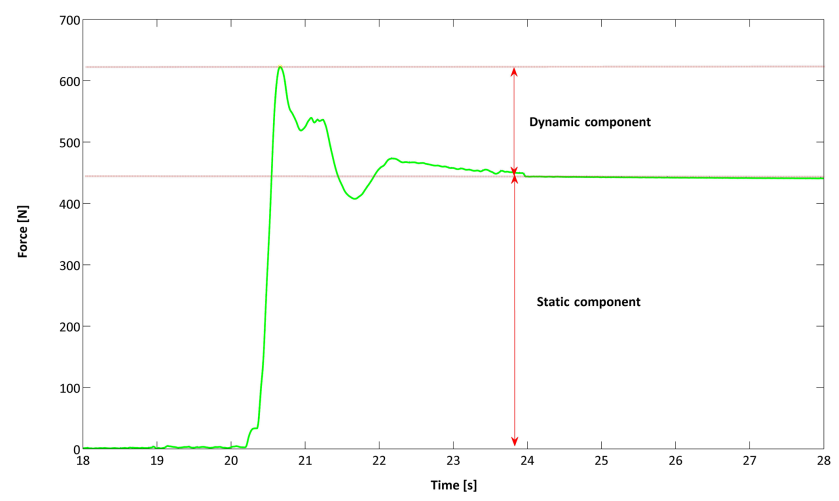

Figure 5. Total impact force measured at load cells vs. time; the static and the dynamic component are highlighted.

behaviour is predominant and one in which dynamic effects, due to the formation of a vertical jet-like wave, contribute to peak force generation. Furthermore, observing the behaviour of the flow in time, the succession of static and dynamic force is justified because the mobilized volume hits against barrier with consecutive surges.

Figure 6 shows the trend of the measured normalized force, $\widetilde{F}$, as a function of the Froude number, $F r$, for the two different channel inclinations $\left(30\right.$ and $\left.35^{\circ}\right)$. The laboratory data have been compared with the equation proposed by Hungr et al. (1984), Armanini and Scotton (1992), Cascini et al. (2000), Huebl and Holzinger (2003), Zanuttigh and Lamberti (2004) and Armanini et al. (2011).

Most of the experimental data fall between the values estimated using Huebl and Holzinger's (2003) equation and Hungr et al.'s (1984) equation with dynamic coefficient equal to 1.5 .

In Eq. (10), the only parameter unknown is the dynamic coefficient $\alpha$ because $n$ can be hypothesized on the basis of the barrier height and the estimated flow thickness.

Figure 7 represents the trend of the proposed equation compared with the experimental data for different inclination of the flume. In particular, it is possible to notice that the major part of the data falls into a region defined by an upper and a lower limit, evaluated, respectively, using the proposed equation with dynamic coefficients equal to 1.2 and 0.5 .

The difference between Fig. 7 $a$ and $b$ is the value of filling ratio, respectively equal to 11 and 9 . The fact that the filling ratio is greater when inclination is greater supports the hypothesis that $n$ is directly related to flow velocity. In fact, a correlation between flow height and velocity has been observed in the laboratory test analysis. Figure 8 clearly shows this correlation: a linear dependence exists between filling ratio (that stores thickness information) and Froude number (that stores velocity information).

According to these observations, the authors want to focus on the trend of the proposed equation: for small Froude number values, relating to the other analysed formulations, 


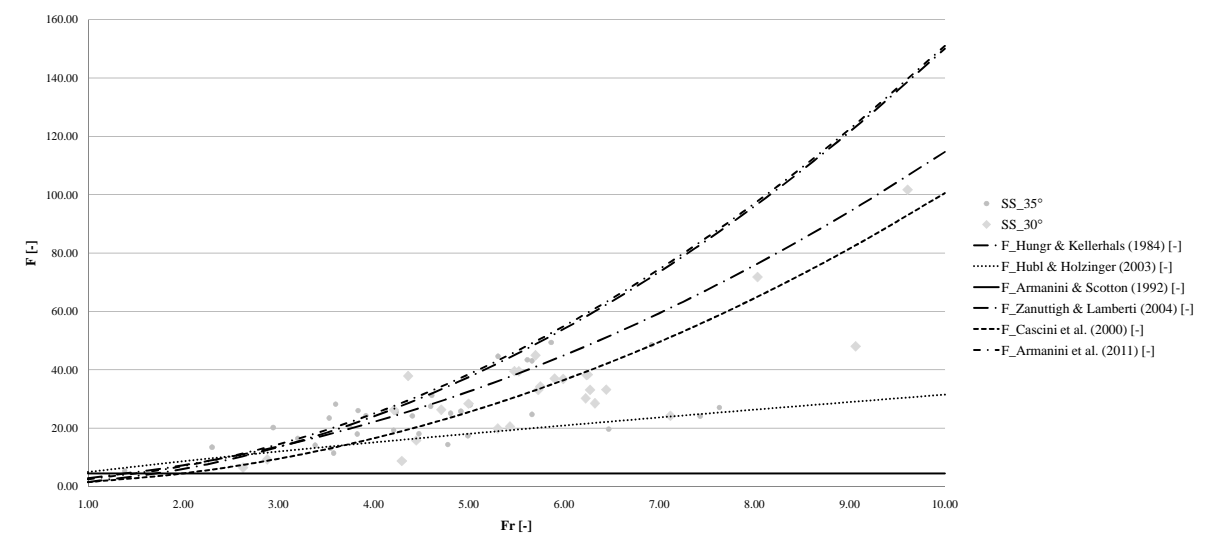

Figure 6. Trend of normalized force measured (points) and predicting model (line) in function of the Froude number. The labels SS_30 and SS_35 ${ }^{\circ}$ correspond to force values evaluated using saturated sand with an inclination of the flume of $30^{\circ}$ (circle points) and $35^{\circ}$ (diamond points), respectively.
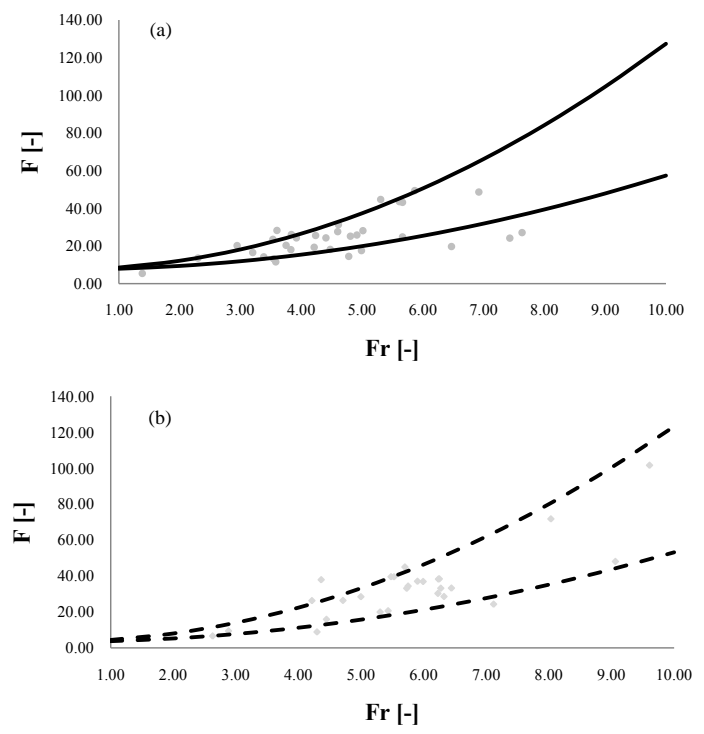

Figure 7. Dimensionless force vs. Froude number for flume inclinations equals to $30^{\circ}$ (a) and $35^{\circ}$ (b): the points fall in a region derived by the proposed model using $\alpha=1.2$ (upper limit) and 0.5 (lower limit). The two regions are obtained using $n=9$ (a) and $n=11$ (b).

it is evident how the static component is predominant compared with the dynamic one. On the other hand, for high values of the Froude number the equation is close to the hydrodynamic models. This means that if the current has small velocity and, therefore, higher flow height, the peak impact force presents a hydro-static behaviour; on the other hand, with high velocity values and small thickness, the hydrodynamic components is relevant and it provides the major contribute for the estimation of impact thrust.

Regarding the variation of dynamic coefficient, it is extremely influenced by the formation of the vertical jet like wave. The fact that $\alpha$ is not much higher than the unity con-
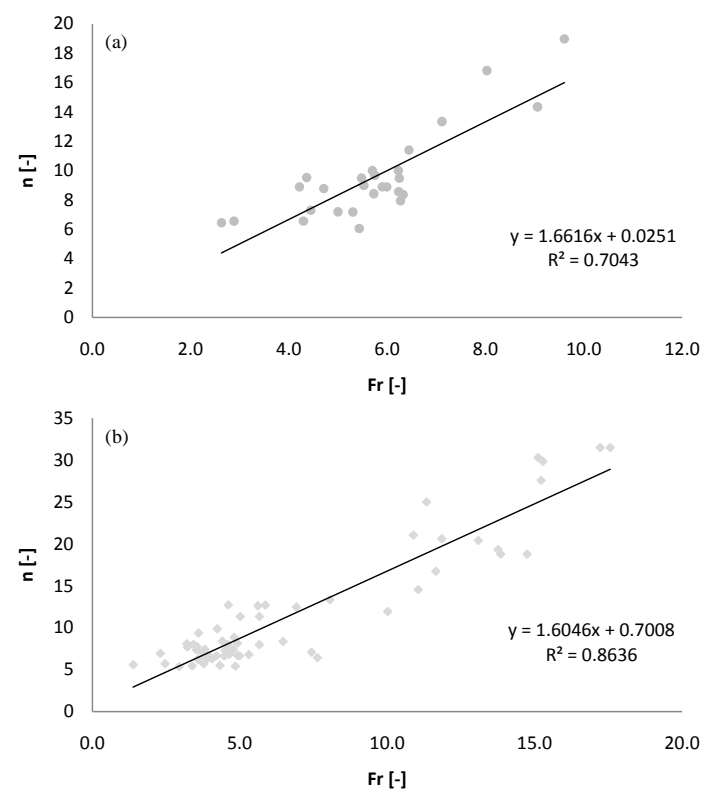

Figure 8. Linear correlation between filling ratio, $n$ and Froude number, $\mathrm{Fr}$ for dataset obtained respectively by flume inclination equal to $30^{\circ}$ (a) and $35^{\circ}$ (b).

firms the goodness of experimental tests; moreover, it suggests that the filling of the barrier occurs for a succession of surges and the peak force is not influenced by overpressure due to reflected waves.

\section{Conclusion}

This study has the aim of reviewing the dynamics of debris flow impact against rigid structures and providing a new simple formulation to predict peak thrust. 
The equation proposed differs from other formulations because takes into account either flow characteristics, material properties and barrier dimensions. It could easily be used to safely design protection barriers, considering the filling ratio to be the ratio between barrier height and flow thickness.

The model developed has a good capability to predict the forces measured during the laboratory tests. Further studies should be done to verify and, if necessary, to adjust this equation comparing with data obtained from real case events.

Acknowledgements. The authors would like to acknowledge the Consorzio Triveneto Rocciatori (CTR) for its financial support of part of this project.

Edited by: T. Glade

Reviewed by: two anonymous referees

\section{References}

Arattano, M. and Franzi, L.: On the evaluation of debris flows dynamics by means of mathematical models, Nat. Hazards Earth Syst. Sci., 3, 539-544, doi:10.5194/nhess-3-539-2003, 2003.

Armanini, A.: On the dynamic impact of debris flows, Recent developments on debris flows, in: Lecture notes in Earth Sciences, edited by: Armanini, A. and Michiue, M., Springer, Berlin, 208224, 1997.

Armanini, A. and Scotton, P.: Experimental analysis on the dynamic impact of a debris flow on structures, Proceedings of the Internationl Symposium Interpraevent, Bern, Switzerland, 107-116, 1992.

Armanini, A., Larcher, M., and Odorizzi, M.: Dynamic impact of a debris flow front against a vertical wall, Ital. J. Eng. Geol. Environ., 1041-1049, 2011.

Bagnold, R. A.: Interim report on wave-pressure research, J. Inst. Civ. Eng., 12, 201-226, 1939.

Brighenti, R., Segalini, A., and Ferrero, A. M.: Debris flow hazard mitigation: a simplified analytical model for the design of flexible barriers, Comp. Geotech., 54, 1-15, 2013.

Bugnion, L., Mc Ardell, B. W., Bartelt, P., and Wendeler, C.: Measurements of hillslope debris flow impact pressure on obstacles, Landslides, 9, 179-187, 2011.

Burkalow, A.: Angle of repose and angle of sliding friction: an experimental study, Geol. Soc. Am. Bull., 56, 669-707, 1945.

Canelli, L., Ferrero, A. M., Migliazza, M., and Segalini, A.: Debris flow risk mitigation by the means of rigid and flexible barriers experimental tests and impact analysis, Nat. Hazards Earth Syst. Sci., 12, 1693-1699, doi:10.5194/nhess-12-1693-2012, 2012.
Cascini, L., Guida, D., Nocera, N., Romanzi, G., and Sorbino, G.: A preliminary model for the landslides of May 1998 in Campania Region, in: Proceeding of the 2nd Int. Symposium on Geotechnics of Hard Soil-Soft Rock, Napoli, Balkema, 1623-1649, 2000.

Costa, J. E.: Physical geomorphology of debris flows, in: Developments and Applications of Geomorphology, Springer-Verlag, Berlin, Germany, 1984.

Daido, A.: Impact force of mud debris flows on structures, Technical Session B, Proceedings of the XXV IAHR Congress, Tokio, Japan, 211-213, 1993.

Huebl, J. and Holzinger, G.: Kleinmassstaebliche Modellversuche zur Wirkung von Murbrechern, WLS Report 50, Institut fur Alpine Naturgefahren, Wien, 3 pp., 2003.

Hübl, J., Suda, J., Proske, D., Kaitna, R., and Scheidl, C.: Debris flow impact estimation, Proceedings of the 11th International Symposium on Water Management and Hydraulic engineering, Ohrid, Macedonia, 137-148, 2009.

Hungr, O., Morgan, G. C., and Kellerhals, R.: Quantitative analysis of debris torrent hazard for design of remedial measures, Can. Geotech. J., 21, 663-667, 1984.

Jiang, Y. J. and Zhao, Y.: Experimental investigation of dry granular flow impact via both normal and tangential force measurements, Geotech. Lett. 5, 33-38, 2015.

Iverson, R. M.: The physics of debris flows, Rev. Geophys., 35, 245-296, 1997.

Lichtenhahn, C.: Die Berechnung von Sperren in Beton und Eisenbeton, Kolloquium on Torrent Dams, Heft, Mitteilungender Forstlichen Bundensanstalt Wien, Wien, 91-127, 1973.

Longo, S.: Analisi dimensionale e modellistica fisica, in: Principi e applicazioni alle scienze ingegneristiche, Springer-Verlag Italia, Milano, Italy, 2011.

Scheidl, C., Chiari, M., Kaitna, R., Mullegger, M., Krawtschuk, A., Zimmermann, T., and Proske, D.: Analyzing debris-flow impact models, based on a small scale modelling approach, Surv. Geophys., 34, 121-140, 2013.

Scotton, P. and Deganutti, A. M.: Phreatic line and dynamic impact in laboratory debris flow experiments, Proceedings of the 1st ASCE International Conference on Debris-flow Hazard Mitigation: Mechanics, Prediction and Assessment, San Francisco, USA, 777-786, 1997.

Zanuttigh, B. and Lamberti, A.: Experimental analysis of the impact of dry granular debris flows against obstacles, XXIX Convegno di idraulica e costruzioni idrauliche, Trento, 571-578, 2004.

Zhang, S.: A comprehensive approach to the observation and prevention of debris flows in China, Nat. Hazards, 7, 1-23, 1993. 